\title{
SELECTION OF A FIELD TESTING METHOD FOR KARST ROCK MASS DEFORMABILITY BY MULTI CRITERIA DECISION ANALYSIS
}

\author{
Danijela Marčić ${ }^{1}$, Anita Cerić $^{2}$, Meho Saša Kovačević ${ }^{3}$ \\ Faculty of Civil Engineering, University of Zagreb, Kačićeva 26, 10000, Zagreb, Croatia \\ E-mails:1djk@grad.hr; ${ }^{2}$ anita@grad.hr; ${ }^{3}$ msk@grad.hr (corresponding author) \\ Received 20 Jun. 2011; accepted 23 Aug. 2011
}

\begin{abstract}
The rock mass deformation modulus is an essential parameter for any numerical analysis and prediction of deformation in geotechnical engineering. Experience acquired using a large number of geotechnical projects in Croatia and the world indicates a somewhat unreliable determination of rock mass deformability based on correlation of classification results. The method of field testing for deformability can provide a more reliable insight into rock mass behaviour under loading conditions. The paper presents the most frequently used methods for field testing rock deformability. The benefits and disadvantages are shown of each particular method used in determining criteria and forming a ranking list of test methods using the multi criteria decision analysis. This ranking list of terrain testing for the rock mass stiffness is acquired on the basis of set criteria, assumes guidelines for compiling an exploratory works plan necessary for designing complex geotechnical structures in karst. Appropriate analyses of the sensitivity to changes in the significance of particular criteria was carried out including its effect on selecting the field method for testing karst rock mass deformability.
\end{abstract}

Keywords: karst, deformability, field testing method, multi criteria analysis, AHP.

Reference to this paper should be made as follows: Marčić, D.; Cerić, A.; Kovačević, M. S. 2013. Selection of a field testing method for karst rock mass deformability by multi criteria decision analysis, Journal of Civil Engineering and Management 19(2): 196-205.

\section{Introduction}

Determining rock mass deformability represents one of the most important tasks in conducting a stressstrain analysis in rock engineering. Rock is heterogeneous, anisotropic and discontinuous. Rock mass deformation depends on the level of rock mass fragmentation, compressibility of discontinuities and compressibility of intact rock material between the discontinuities. Karst is macroporous material and its engineering properties strongly depends on discontinuities, including porosity (Jespersen et al. 2010).

For design purposes rock mass deformation is most often determined on the basis of rock mass classification systems results (Aksoy et al. 2010). Most used are RQD (Jiang et al. 2009), Q (Barton 2007), RMi (Palmstrom, Singh 2001), RMR (Chun et al. 2009) and GSI (Russo 2009) classifications. The link between deformability and rock classification results may be established using field testing results or with the aid of numerical back-analysis based on the results of measuring the deformation of geotechnical structures carried constructed in rock masses.

In recent years, artificial intelligence systems such as genetic programming (Beiki et al. 2010), back propagation neural networks (Majdi, Beiki
2010) and fuzzy models (Tutmez, Terkan 2007) were used to predict the rock mass deformation modulus.

All classifications are based on a point system whereby certain parameters are associated with various numerical values and a dependency on their importance for the complete behaviour of the rock mass (Aksoy 2008). When considering that all the classification parameters cannot be unambiguously measured or assessed for greater rock mass volumes, it is clear that determination of the stiffness and parameters for the calculation using classifications in a large number of cases will be affected by a significant unreliability or risk (Kovačević et al. 2011).

During the last 15 years a large number of geotechnical projects have been carried out in Croatia due to large infrastructure construction projects. Determining rock mass deformability on the basis of rock mass classification results is ordinarily applied in Croatian geotechnical practice (Brunčić et al. 2010). Karst morphology features cover more than half (54\%) of Croatia, or over $70 \%$ if one takes into account the Croatian Adriatic submarine environment where carbonate rock formations that undergo karstification are predominant (Garašić et al. 2010). Extensive measuring during geotechnical projects constructed on 
carbonate rock formations have shown that the measured deformations are significantly greater than those obtained in calculations in which deformability parameters gained using existing links with rock mass classifications and that the measured forms of deformations based on depth are significantly different than those calculated (Jurić-Kaćunić et al. 2011).

The stated experience indicates the importance of optimally determining a method, the number and position of field investigations for deformation moduli and a return to the original concept of the use of classification in determining rock mass deformability which is given by Bieniawski (1978). He has suggested that classification can be used to determine an expected modulus with a $20 \%$ precision, and that on the basis of this a field testing program can be drawn up. He proposes, for example, that if a high deformation modulus is expected to exceed $30 \mathrm{GPa}$ and if the classification concludes that the rock formation is relatively uniform, only a number of field tests will be needed. However, if the deformation modulus is expected to be less than $10 \mathrm{GPa}$ for a relatively varied rock structure, it then becomes essential to devise an extensive field exploratory plan.

By taking into account that field testing of karst stiffness in Croatia has not been previously conducted, this paper proposes the formation of a ranking list for field testing deformability in rock masses using multi criteria decision analysis. Such a ranking list for field testing rock mass deformability, obtained on the basis of set criteria, would represent guidelines in drawing up the exploratory works plan which is necessary for designing complex geotechnical projects in rock (tunnels, steep slopes, bridge foundations, etc.). The results of the conducted multi criteria analysis would be a good starting point for works contractors when deciding whether to invest in the procurement of equipment and what equipment to choose.

Applications of multi criteria analyses in different areas of civil engineering are recently presented by Zavadskas and Antucheviciene (2007) and Sivilevičius et al. (2012).

\section{Test methods for rock mass deformability}

Field testing for deformability is based on loading and unloading a particular volume of rock mass and measuring deformation caused by defined stresses. The ratio of stress and deformation represents stiffness. The deformation modulus vary with the sizes of samples (Li et al. 2010). To obtain deformation parameters of rock masses it is necessary to test an adequate volume of rock mass which includes a representative number of discontinuities (Isik et al. 2008). The methods of field testing stiffness encompasses various volumes of rock mass that are in most cases significantly greater than laboratory samples and as such may represent rock mass behaviour.
The International Society of Rock Mechanics (ISRM) recommends the following field testing for stiffness in rock masses: plate loading test, radial jacking test, large flat jack test and flexible or stiff dilatometers.

\subsection{Plate loading test}

Plate loading test is based on determination of the deformation modulus by measuring the displacement of rock mass which in turn is caused by the loading of a circular plate possessing an appropriate diameter. The test procedure, appropriate equipment for testing and calculation for the deformation modulus on the basis of measured results is presented in detail in ISRM (1979).

When foundations for heavy buildings situated on rock (dams, bridges, etc.) are in question, a plate loading test is conducted on the terrain surface. Displacements of rock mass can be measured in the surface centre and also along the depth of the loaded rock mass not only in the centre but also outside of the centre of the plate by installing appropriate extensometers. The advantage of measuring displacement at various depths lies in the fact that rock mass deformation is avoided at contact points, significantly reducing the obtained deformation modulus if the measured displacement is only on the surface. The recommended range for the plate diameter is $0.5-1.0 \mathrm{~m}$. Larger plate diameters are better since they encompass a larger volume of tested rock mass, but they also demand a significantly larger loading for achieving the desired stress.

In cases relating to foundations for exceptionally large structures where it is necessary to identify the diameter of the deformation modulus with respect to depth, plate testing is used in large-diameter wells at various depths.

When designing underground garages where it is necessary to identify the deformation modulus at large depths, the test is carried out in tunnels or galleries

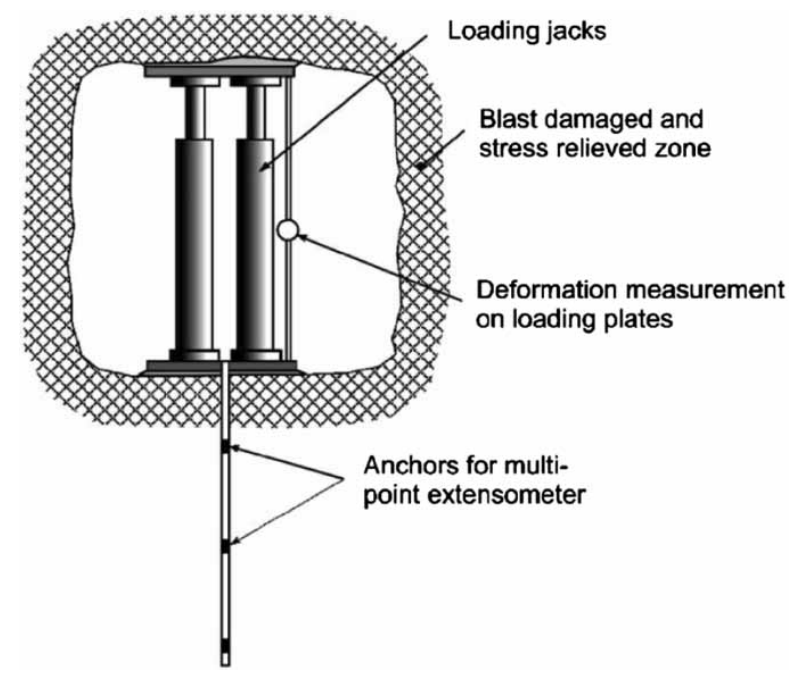

Fig. 1. Plate loading test (Hoek, Diederichs 2006) 


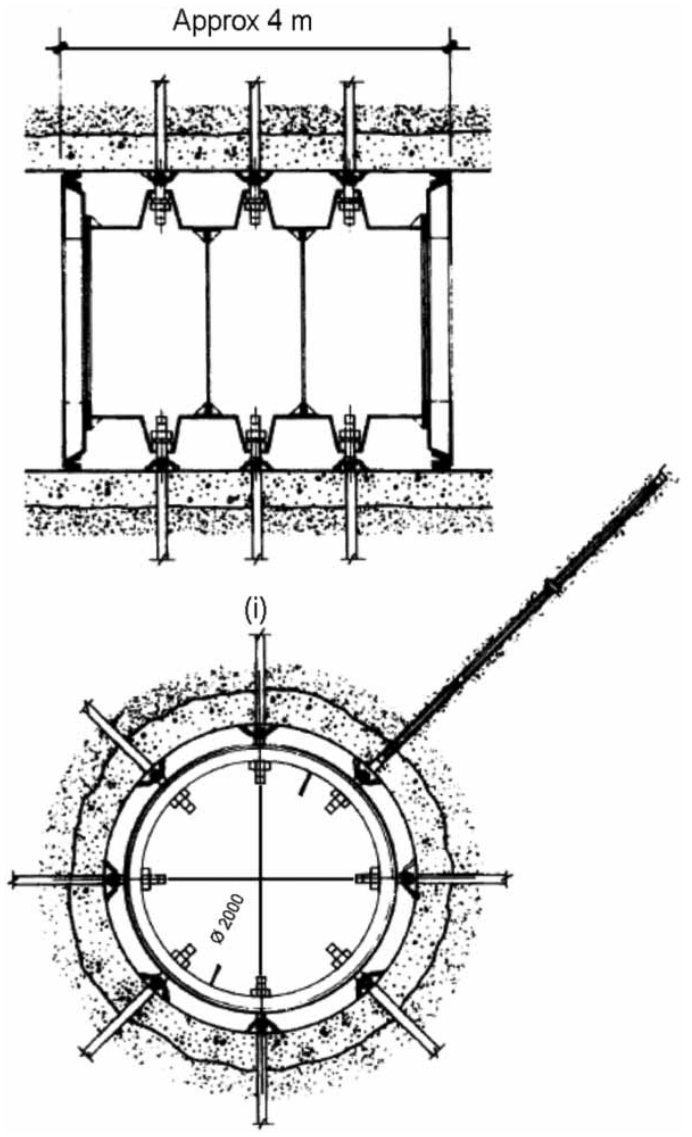

Fig. 2. Radial jacking test in a pressure chamber (ISRM 1979)

specially constructed for testing purposes or at the start of tunnel sections under construction (Fig. 1).

The test is carried out by incremental loading and releasing the load on the plate up to the maximum stress which should be 1.2 to 1.5 times greater than the expected stress during exploitation. The duration of a single loading increment is 24 hours after which the loading is released over the same period. In the event that the deformation is not completed within 24 hours, it then becomes necessary to extend the loading duration. The recommendations are to achieve maximum stress using at least 5 increments or 5 cycles for loading and releasing.

\subsection{Radial jacking test}

Radial jacking test is based on determining the deformation modulus by measuring rock mass displacements caused by radial loading of rock mass. The test procedure, necessary test equipment and the calculation for the deformation modulus is based on measured results presented in detail in ISRM (1979).

Radial jacking is carried out using hydraulic presses or water pressure (Fig. 2), while displacements along the depth of the rock mass are measured using inserted extensometers.

It is used for the requirements of foundations in large dams and other heavy structures, where the test is carried out in test chambers possessing a circular perpendicular cross-section with a large radius or in the initial sections of tunnels, where testing is then conducted using a ratio of 1:1. It encompasses a large volume of rock mass and consequently represents in the best manner the rock mass with all its weaknesses and discontinuities, and it is also possible to test in rock masses the level of anisotropy and stiffness.

The test is conducted using radial jacking and unloading of rock mass with average incremental loading and unloading at $0.05 \mathrm{MPa} / \mathrm{min}$. Once reaching the maximum pressure, the displacements are measured up to the point where deformation ceases. It is recommended that maximum stress be achieved in at least 3 cycles of loading and unloading.

\subsection{Large flat jacks}

Testing using large flat jacks is based on determining the deformation modulus by measuring rock mass displacements which in turn are caused by increasing pressure in large flat jacks inserted into previously made slots in the rock mass. The test procedure, necessary testing equipment and calculations for the deformation modulus on the basis of measured results are presented in detail in ISRM (1986).

The flat jacks consist of two steel plates at least $1 \mathrm{~mm}$ thick, welded along the edge, between which oil is inserted. The shape of the flat jack is a $1 \mathrm{~m}$ long side quadrant from which a $1 \mathrm{~m}$ semi-circle extends (Fig. 3). The jack has a single opening used as an oil inlet, increases pressure and changes the jack width as well as other openings for releasing air and electrical conductors used to transmit measure rock mass

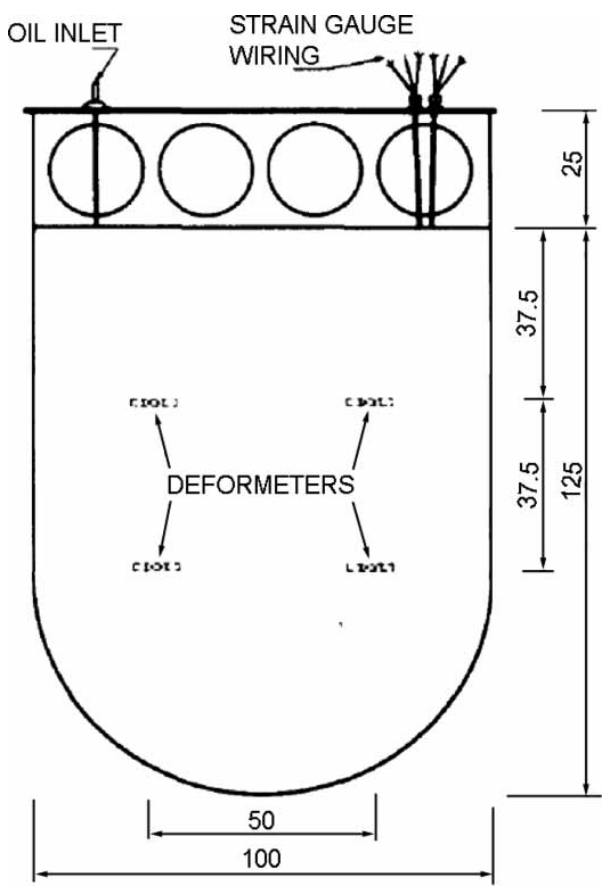

Fig. 3. Large flat jack (ISRM 1986) 
displacements to metering devices. Rock mass displacement are measured perpendicular to the surface accommodating jacks with four short deformeters located within the flat jack or in a particular well.

The test is applied to all significant geotechnical structures that are constructed on rock mass. It encompasses a greater volume of rock mass than the plate loading test, but less volume than the radial jacking test in tunnels. Placing the flat jacks in various directions allows testing the level of anisotropy and stiffness in rock masses.

Prior to conducting the test, it is necessary to construct slots using a large diamond saw in the rock mass at a specified depth and $6 \mathrm{~mm}$ wide. When covering a larger volume, a larger number of flat jacks can be inserted in the slot along a particular plane.

The test is conducted using at least three cycles of loading and unloading until the difference in total deformation for maximum and minimum loads in the last two cycles does not exceed $5 \%$ of total deformation. The maximum pressure should be 1.2-1.5 times greater than the maximum expected stress in exploitation.

\subsection{Flexible dilatometer}

Testing the stiffness of rock masses using flexible dilatometers is based on the principle of measuring changes in borehole radiuses caused by radial expansion of the dilatometer probes placed a certain depths. The test procedure, equipment necessary for testing and calculating the deformation modulus on the basis of measurement results is presented in detail in ISRM (1987).

Radial loading of borehole walls is carried out by expansion of the flexible dilatometer membrane with increasing pressure in the dilatometer probe, hydraulically, assisted by compressed air, oil or water. The flexible membrane transfers the load distribution along the borehole walls in an even manner.

Two types of dilatometer probes are used for measuring the radius changes in borehole. The first type of probe (Fig. 4) registers changes in the borehole

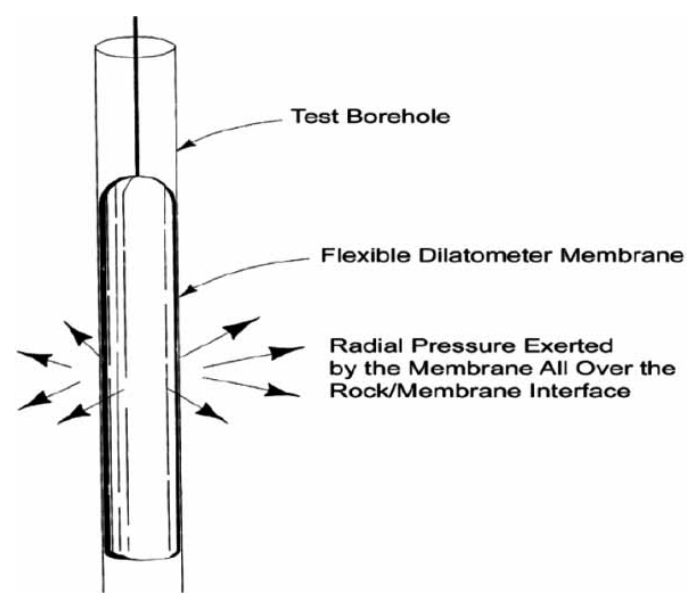

Fig. 4. Flexible dilatometer (USBR 2009) volume and calculates radius changes. The second type of probe measures directly changes in the borehole's radius aid by incorporated meters.

Great importance in applying and developing dilatometer testing was the fact that this type of testing relatively quickly carries out a number of tests within a single borehole and therefore obtains the distribution of rock mass deformation characteristics based on depth. This is a significant advantage of dilatometer testing compared to other tests which measure deformation characteristics solely in the loaded surface area.

The test is carried out using at least three loading and unloading cycles. The applied pressure should be as much as possible so that the deformation process includes the greatest possible volume of rock mass, but does not exceed the pressure permitted by the testing equipment. In each new loading cycle, the maximum pressure should be increased so that in the event of membrane damage, the test results sourced from smaller pressures may be used.

\subsection{Stiff dilatometer}

Testing rock mass stiffness using stiff dilatometers is carried out by measuring radius changes in borehole caused by expansion of the stiff dilatometer probe placed at particular depths. The test procedure, equipment necessary for testing and calculations of the deformation modulus on the basis of measurement results is described in detail in ISRM (1996).

The loading on the rock mass is transmitted across two rigidly bent dilatometer plates. Their mutual displacement is caused by hydraulically increasing pressure in the dilatometer probe using compressed air, oil or water. The rigid plate transfers the distributed displacement uniformly along the whole testing area.

The dilatometer is better known as the NX borehole Jack, i.e. the Goodman Jack (Fig. 5). Various

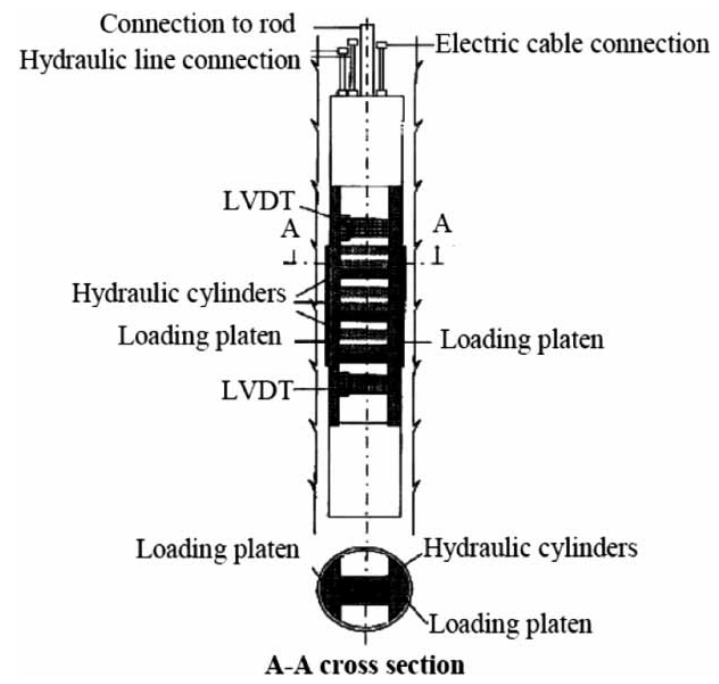

Fig. 5. Stiff dilatometer (Göktepe et al. 2011) 
dilatometer models may be used for stiff and softer rock masses.

As in the case of the flexible dilatometer, a number of tests can be carried out rather quickly in a single well and therefore the rock mass deformation distribution characteristics according to depth can be obtained, which is a significant advantage over other tests used for testing deformation properties solely in loaded area.

The test commences aims to achieve a continuity of the displacement between the well walls and the stiff dilatometer plates. Measuring distances is carried out using two meters with readings variations not exceeding $0.5 \mathrm{~mm}$. The maximum desired pressure should be applied in at least 10 equal increments.

\section{Criteria for selecting a test method}

The dependency of the deformation modulus on classification results, adjusted to karst conditions in Croatia, was researched and determined using numerical back-analysis, and based of measured deformation results in geotechnical structures built on rock mass (Jurić-Kaćunić et al. 2011).

Taking into account that field deformability tests in Croatian karst have not been previously carried out up, this paper proposes the forming of a ranking list of field tests for rock mass deformability using multicriteria decision analysis.

In regards to geotechnical structures built on rock masses, assessing the significance of criteria represents consistent fulfilment of the interests of the investor, the test conductor and the design engineer.

The lowest price for testing or least cost of implementing the exploratory works plan, essential for a safe design of geotechnical structures in rock masses, is always the investor's greatest interest. Naturally, the contractor's interest in testing is completely the opposite. The investor has the advantage due to the fact that field testing for deformability in karst in Croatia has not been conducted previously, and a large number of geotechnical structures have been designed and carried out on the basis of results gained from classifying rock mass. The design engineer is conscious of the fact that a higher price for testing leads to more reliable determination of the deformation modulus and that from an engineer's point of view, any direct field testing of the deformation modulus is better than indirect determination based on correlation of results obtained from classifying rock mass.

The duration of the test and implementation of the exploratory works plan in a large number of cases represents exceptionally important criteria in selecting a test method. Once making a decision on commencing the project, the investor endeavours to optimally reduce the time required for drawing up the design documentation which incorporates field exploratory works. In this way, more time will be available for construction. The design engineer is conscious of the fact that in such cases, reducing the duration of testing negatively impacts the quality of obtained results which then serve as a basis for design, but this in turn provides more time for a better quality design.

The complexity of testing directly impacts the quality of the obtained rock mass deformation moduli (Hoek, Diederichs 2006). More complex testing requires large equipment investments by the contractor, including investing in well trained and highly qualified personnel. Experience has shown that this is rarely proportional to revenue gained from such testing. Consequently, it comes as no surprise that the contractor conducting testing shows little interest in carrying out more complex testing and here he has the support of the investor since more complex testing always costs more and lasts longer. On the other hand, the design engineer has a great interest in conducting complex testing that will provide better quality results but will not last too long.

The volume of rock mass included in the test has a large impact on the test results and subsequently has a greater significance for the design engineer and represents his greatest interest. Laboratory testing of the stiffness of core samples covers a volume of $2 \times 10^{-4} \mathrm{~m}^{3}$ and as such does not represent good rock mass behaviour for larger volumes. Field testing the stiffness of rock mass covers a significantly larger volume of rock mass than laboratory testing and some may represent quite good rock mass behaviour. Such testing using flexible and stiff dilatometers includes a volume of $0.1 \mathrm{~m}^{3}$, the plate loading test includes a rock mass volume of around $2 \mathrm{~m}^{3}$, the radial jacking test includes a volume of around $1000 \mathrm{~m}^{3}$ whereas the large flat jack test includes a volume of around $10 \mathrm{~m}^{3}$ (He 1993). A comparison of results using various methods in field testing stiffness suggests that caution should be taken when interpreting results. The deformability of a quality and relatively uniform rock mass significantly depends on the test method. Testing encompassing a larger volume of rock mass resulted in a smaller deformation modulus and smaller dissipation of results.

Taking into account the above said, the following criteria for forming a ranking list of methods used for field testing rock mass deformability include:

1. Lowest test price;

2. Shortest test duration;

3. Least complex testing;

4. Largest included test volume;

5. Least disturbance of rock mass during testing.

\section{Analytic Hierarchy Process (AHP)}

In establishing the ranking list of field tests for rock mass deformability the multi criteria analysis AHP method was used. AHP was developed by Saaty (1980) 
as an aid to managers in making decisions. By incorporating subjective assessments and objective facts into a logical hierarchal framework, AHP provides the decision maker with an intuitive and reasonable approach to quantifying the importance of each decision element by using a mutual comparison process. This process allows decision makers to reduce a complex problem to a multi-level hierarchal form (Cerić, Marić 2011). At the same time AHP is well mathematically grounded (Podvezko 2009).

Generally, the hierarchy has at least three levels: goal, criteria and alternatives. Criteria may have subcriteria. The process starts by determining the relative importance of particular alternatives with respect to the criteria and the sub-criteria. Then the criteria are compared with respect to the goal. Finally the results of these two analyses are synthesised by calculating the relative importance of the alternatives with respect to achieving the goal. The process of comparison is represented by forming a comparative matrix. If the analyst has at his disposal $\mathrm{n}$ alternatives, or criteria that form the comparative matrix, then he must make $n(n-1) / 2$ evaluations. The eigenvector of each comparative matrix is the priority list, while the eigenvalue gives the measure of consistency in making the assessment or comparison. The synthesised eigenvector is the global sequence of the alternatives with respect to achieving the goal. A global consistency coefficient smaller than 0.10 is acceptable, otherwise the assessments must be revised. AHP can best be used for multi-criteria problems in which it is not possible to precisely quantify how alternatives impact decision-making.

Forming comparative matrices of relative significance for criteria with respect to the goal and for alternatives with respect to the criteria was carried out with the assistance of 18 experts from the scientific community, design engineers, contractors and investors. These people had, in various ways, a significant contribution in important geotechnical projects in the past and expected significant participation in future projects.

The software program Expert Choice (version. 11.0) was used carrying out the multi criteria analysis via the AHP method.

\subsection{Hierarchical structure}

The model comprises the goal, five criteria and five alternatives. The goal is to establish a ranking list obtaining field tests for rock mass deformability in Croatian karst.

The criteria are: 1 . Price; 2. Duration; 3. Complexity; 4. Volume; and 5. Disturbance.

Alternatives are methods for field testing rock mass rigidity: 1 . Plate loading test; 2 . Radial jacking test; 3. Large flat jack test; 4 . Flexible dilatometer; and 5. Stiff dilatometer.
Table 1. Comparison of criteria with respect to goal

\begin{tabular}{lcrrrr}
\hline Criteria No. & 1 & 2 & 3 & 4 & 5 \\
\hline 1 & $1 / 1$ & $1.5 / 1$ & $3.5 / 1$ & $1 / 2.5$ & $3 / 1$ \\
2 & $1 / 1.5$ & $1 / 1$ & $4 / 1$ & $1 / 2$ & $2 / 1$ \\
3 & $1 / 3.5$ & $1 / 4$ & $1 / 1$ & $1 / 8$ & $1 / 2$ \\
4 & $2.5 / 1$ & $2 / 1$ & $8 / 1$ & $1 / 1$ & $4 / 1$ \\
5 & $1 / 3$ & $1 / 2$ & $2 / 1$ & $1 / 4$ & $1 / 1$ \\
\hline
\end{tabular}

\subsection{Comparison of criteria with respect to goal}

Table 1 shows a comparative matrix of relative significance for criteria with respect to the goal. The matrix is formed on the basis of assessments by 18 experts who are in fact design engineers, contractors and investors and who have in various ways had a significant role in carrying out important geotechnical projects in the past and shall continue doing so in the future. The investor's aim is to reduce as much as possible the price and costs of testing, the contractor wants the least complex test methods while the design engineer is interested in covering the maximum possible volume and the least possible rock mass deformation during testing. A total of 10 assessments were conducted. The experts participating in the assessment concluded for example that the criterion Complexity has eight times less significance than the criterion Volume, and that the criterion Duration has twice the significance of the criterion Disturbance.

Consistent evaluation using the AHP method and resolving the generalised problems of eigenvalues gave the eigenvector of the comparative matrix, thus presenting the rank list of criteria significance with respect to the goal (Fig. 6).

The greatest significance has Volume $(43.3 \%)$, followed by Price (22.9\%), Duration (19\%), Disturbance (9.5\%) and finally Complexity (5.3\%). In this example, investors have somewhat subordinated their interests to the interests of the profession since the design engineer's key interests (Volume and Disturbance) overall have an above half relative significance $(52.8 \%)$. Each project is different and these relations are different depending on the composition of decision-makers, the importance of the

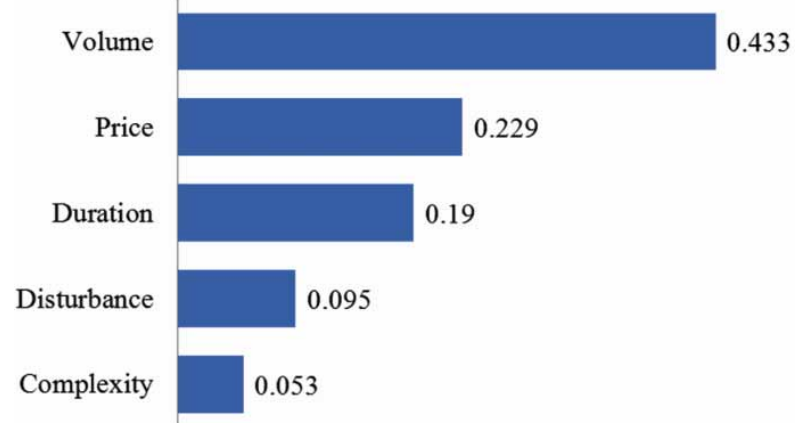

Fig. 6. Criteria significance with respect to goal 
geotechnical structure and certain criteria specific for each particular project.

\subsection{Comparison of alternatives with respect to criteria}

The testing price for each particular method can be calculated when designing and building a particular structure on rock masses. Therefore, the mutual relation of particular field tests in regards to price can be assessed objectively. The greatest significance is gained by the least expensive method.

Based on the exploratory works program, i.e. the required number of particular field tests for a characteristic structure and duration of each particular testing, it is possible to objectively evaluate the mutual significance of particular field tests with respect to the total duration of the exploratory works plan. The greatest significance is gained by the quickest method.

Since very different field testing methods are involved, it is necessary to evaluate the relative complexity of particular methods with respect to other methods. The complexity of testing significantly impacts the quality and reliability of obtained test results and rock mass stiffness.

Representative and reliable test results to a great extent depend on the volume of tested rock mass. The greater the volume, the more reliable the test results.

Vibrations caused by earth tremors, construction works or field tests cause deformations in rock masses, increasing its fragmentation and therefore reducing rigidity. Consequently, great importance is placed on the methods that exert least possible rock mass deformation during testing.

Table 2 shows a comparative matrix of relative significance for alternatives with respect to the criterion Disturbance. Experts included in the assessment concluded for example that the large flat jacks deform rock mass five times less than the radial jacking test, and that the stiff dilatometer deforms rock mass four times less than the plate loading test.

\subsection{Synthesis of comparison results}

Once all consistent evaluations have been made and all comparative matrices possessing relative significance for alternatives with respect to criteria have been determined, the AHP method provides the global eigenvector of the synthesised comparative matrix

Table 2. Comparison of alternatives with respect to criteria Disturbance

\begin{tabular}{lrcccl}
\hline Altern No. & \multicolumn{1}{c}{1} & 2 & 3 & 4 & 5 \\
\hline 1 & $1 / 1$ & $2 / 1$ & $1 / 2.5$ & $1 / 5$ & $1 / 4$ \\
2 & $1 / 2$ & $1 / 1$ & $1 / 5$ & $1 / 10$ & $1 / 8$ \\
3 & $2.5 / 1$ & $5 / 1$ & $1 / 1$ & $1 / 2$ & $1 / 1.6$ \\
4 & $5 / 1$ & $2 / 1$ & $10 / 1$ & $1 / 1$ & $1 / 1.3$ \\
5 & $4 / 1$ & $2 / 1$ & $1.6 / 1$ & $1.3 / 1$ & $1 / 1$ \\
\hline
\end{tabular}

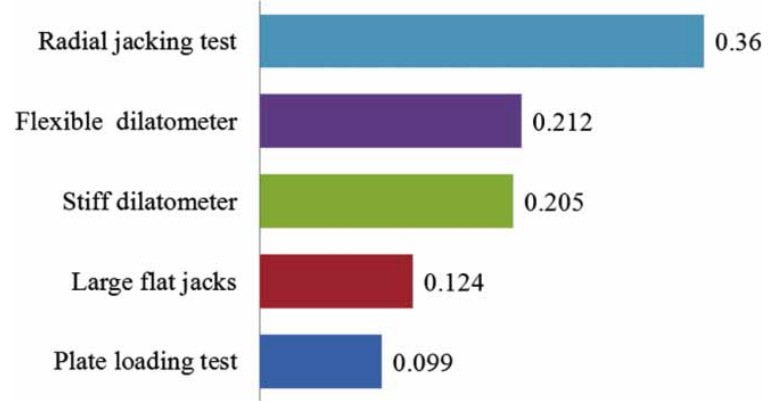

Fig. 7. Ranking list of field tests used in determining rock mass deformability

representing the rank list of alternative significances with respect to the goal.

Fig. 7 shows the results of the multi criteria analysis, i.e. the ranking list of field tests for determining rock mass deformability.

First on the ranking list is the radial jacking test with a $36.0 \%$ "stake". This high position, despite the high price and long test duration, has brought about criterion significance Volume with respect to other criteria and an exceptionally large volume which this test method includes.

The second and third position is flexible and stiff dilatometer at $21.2 \%$ and $20.5 \%$ "stake". These are the least expensive, quickest and simplest tests and tests that least disturb the rock mass. The disadvantage is that it includes a relatively small volume for testing.

The fourth and fifth place is assumed by testing large flat jack test and plate loading test with a $12.4 \%$ and $9.9 \%$ "stake" respectively.

\section{Sensitivity analysis}

The Export Choice program allows various way of conducting sensitivity analyses. This problem is addressed by the suitable option Dynamic which provides a simple change in weight and significance of a criterion and its influence on the ranking list of field tests for determining rock mass deformability.

The previous analysis provides the greatest criterion significance Volume (43.3\%), nearly twice the size of the criterion significance Price (22.9\%) and Duration $(19.0 \%)$. Therefore, the investor has fully subordinated his interests to the profession, i.e. to the design engineer. This in practice is a very rare case. Most often the investor aims to spend the least possible money on exploratory works so that more money may be available for the main construction, and wants the exploratory works to finish as soon as possible in order to proceed with the compilation of the project design documentation and the actual construction.

Fig. 8 shows a sensitivity analysis by increasing the weight of the criterion Price to $50 \%$ with respect to other criteria. Evidently, a different result was given by 

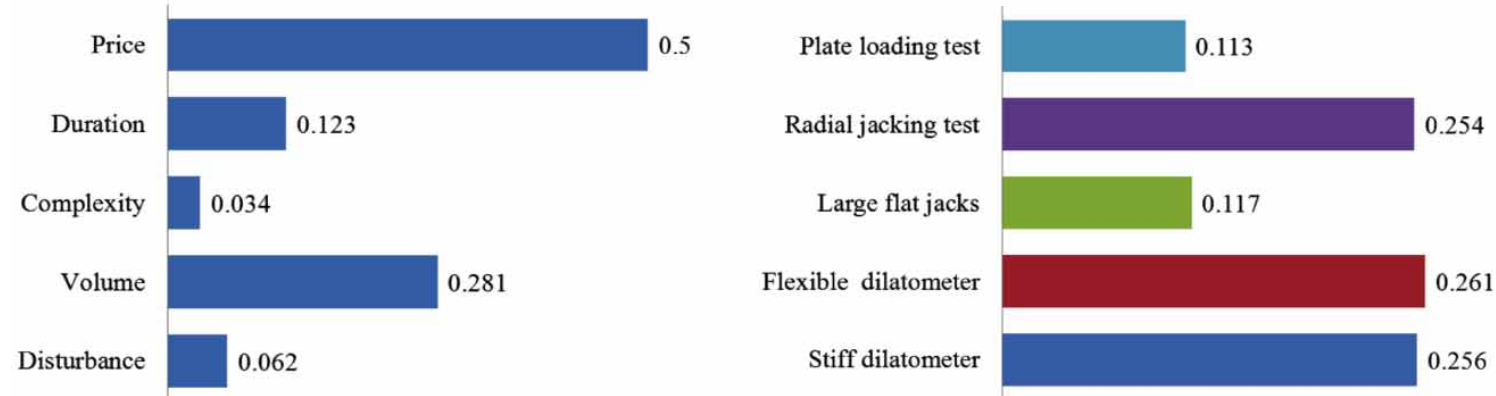

Fig. 8. Sensitivity analysis - increasing the weight of the criterion Price to $50 \%$

the multi criteria analysis. The flexible dilatometer $(26.1 \%)$ and stiff dilatometer $(25.6 \%)$ assumed first and second place respectively, while the radial jacking test $(25.4 \%)$ fell to third place. Furthermore and importantly, the differences in the final tests were only slight, hence in practice all three methods for field testing rigidity should be equally represented if the criterion significance Price is increased to $50 \%$. The flat jacks and jack plates do not alter the significance of their weight nor the sequence on the ranking list.

Fig. 9 shows a sensitivity analysis by increasing the weight of the criterion Duration to $50 \%$ with respect to other criteria. Evidently, a different result was given by the multi criteria analysis. The flexible dilatometer $(27.1 \%)$ and stiff dilatometer $(26.6 \%)$ assumed first and second place respectively, while the radial jacking test $(25.0 \%)$ fell to third place.

Again, the differences in the final tests were only slight, hence in practice all three methods for field testing stiffness should be equally represented if the significance of the criterion Duration is increased to $50 \%$. The flat jacks and jack plates do not alter the significance of their weight nor the sequence on the ranking list.

\section{Conclusions}

Determining the rock mass deformability on the basis of results from rock mass classifications is normally applied in Croatian and world geotechnical practice. Experience gained in constructing a large number of

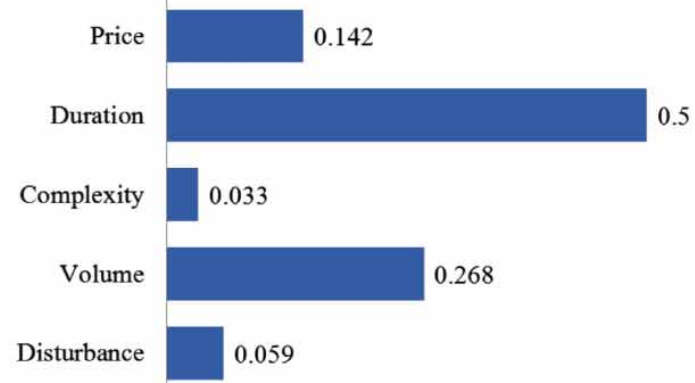

geotechnical projects in Croatia and the world has shown an inadequately reliable determination of rock mass deformability on the basis of existing correlations with the classification results. In order to form reliable correlations, it is essential to conduct field testing for deformability which up until now was not the case.

Laboratory testing of deformability on core samples does not represent rock mass behaviour for larger volumes. A small-dimensioned rock sample does not contain or contains very little discontinuity, behaves as an intact rock and consequently provides significantly larger deformation modulus values than the modulus obtained in field testing.

Field testing of rock mass deformability includes significant larger volumes of rock mass than laboratory samples and some of them may represent rock mass behaviour. On the other hand, testing is very expensive and time consuming, and due to the presumptions in interpreting results, field testing reliability is often ambiguous. A comparison of test results using various methods shows that rock mass deformability significantly depends on the test method.

The most frequently utilised field test methods for rock mass deformability are: plate loading test, radial jacking test, large flat jack test, flexible dilatometer and stiff dilatometer.

Field testing for rock mass deformability requires a lot of time and resources, hence drawing up the field testing plan, especially for large structures is a very difficult and complex task. The reliability and usability of field test results is mostly affected by: lowest

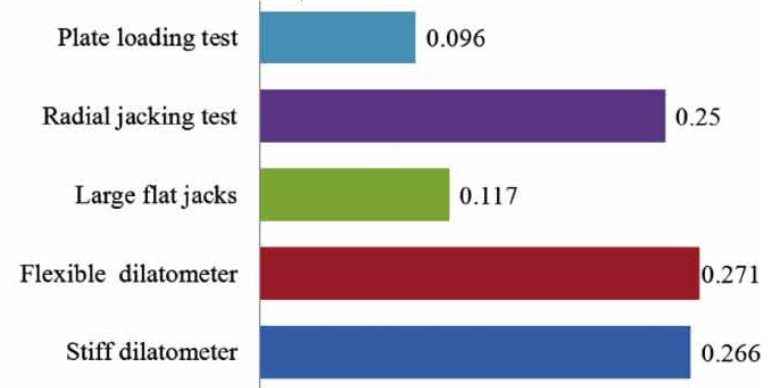

Fig. 9. Sensitivity analysis - increasing the weight of the criterion Duration to $50 \%$ 
possible testing costs, shortest possible testing durations, least complex testing methods, inclusion of the greatest possible volumes for testing and the least possible rock mass disturbance during testing.

A multi criteria decision analysis is used to form a test method ranking list. The method that best takes into account the given criteria and their mutual relationships, despite the high price and duration of testing, is the radial jacking test due to exceptionally large testing volumes. The second and third place is assumed by the flexible dilatometer and stiff dilatometer, the quickest and simplest test that exerts the least deformation in rock masses. Despite this disadvantage, the methods include a small testing volume. The fourth and fifth positions are assumed by large flat jack tests and plate loading tests.

The sensitivity analysis has shown that increasing the significance of the testing criteria Price and Duration provides a different result in the multicriteria analysis. The flexible and stiff dilatometer is practically equated in significance with the radial jacking test. The flat jacks and jack plates do not significantly alter their weight or position on the ranking list.

A ranking list of field testing for rock mass rigidity formed in this way, and obtained on the basis of set criteria represents guidelines for drawing up plans for exploratory works.

\section{References}

Aksoy, C. O. 2008. Review of rock mass rating classification: historical developments, applications, and restrictions, Journal of Mining Science 44(1): 51-63. http://dx.doi.org/10.1007/s10913-008-0005-2

Aksoy, C. O.; Kantarci, O.; Ozacar, V. 2010. An example of estimating rock mass deformation around an underground opening using numerical modeling, International Journal of Rock Mechanics and Mining Sciences 47(2): 272-278.

http://dx.doi.org/10.1016/j.ijrmms.2009.12.001

Beiki, M.; Bashari, A.; Majdi, A. 2010. Genetic programming approach for estimating the deformation modulus of rock mass using sensitivity analysis by neural network, International Journal of Rock Mechanics and Mining Sciences 47(7): 1091-1103. http://dx.doi.org/10.1016/j.ijrmms.2010.07.007

Barton, N. 2007. Rock quality, seismic velocity, attenuation and anisotropy. Rotterdam: Balkema. 729 p.

Bieniawski, Z. T. 1978. Determining rock mass deformability: experience from case histories, International Journal of Rock Mechanics and Mining Sciences \& Geomechanics Abstracts 15(5): 237-247. http://dx.doi.org/10.1016/0148-9062(78)90956-7

Brunčić, A.; Jurić-Kaćunić, D.; Kovačević, M. S. 2010. Projektiranje i izvedba zasjeka u flišnoj stijenskoj masi [Design and realization of side-cuts in flysch rock mas], Gradevinar 62(1): 13-23.

Cerić, A.; Marić, T. 2011. Određivanje prvenstva pri upravljanju rizicima građevinskih projekata [De- termining priorities for managing risk on construction projects], Građevinar 63(3): 265-271.

Chun, B.-S.; Ryu, W. R.; Sagong, M.; Do, J.-N. 2009. Indirect estimation of the rock deformation modulus based on polynomial and multiple regression analyses of the RMR system, International Journal of Rock Mechanics and Mining Sciences 46(3): 649-658. http://dx.doi.org/10.1016/j.ijrmms.2008.10.001

Garašić, M.; Kovačević, M. S.; Jurić-Kaćunić, D. 2010. Investigation and remediation of the cavern in the vrata tunnel on the Zagreb - Rijeka highway (Croatia), Acta Carsologica 39(1): 61-77.

Göktepe, A. B.; Altun, S.; Sezer, A. 2011. Simulation of dilatometer tests by neural networks, Mathematical \& Computational Applications 16(2): 535-545.

He, J. 1993. A case review of the deformation modulus of rock mass. Scale effect, in Proc. of International Workshop on Scale Effects in Rock Masses, 1993, Lisbon. Balkema, 87-91.

Hoek, E.; Diederichs, M. S. 2006. Empirical estimation of rock mass modulus, International Journal of Rock Mechanics and Mining Sciences 43(2): 203-215. http://dx.doi.org/10.1016/j.ijrmms.2005.06.005

Isik, S. N.; Ulusay, R.; Doyuran, V. 2008. Deformation modulus of heavily jointed - sheared and blocky greywackes by pressuremeter tests: numerical, experimental and empirical assessments, Engineering Geology 101(3-4): 269-282. http://dx.doi.org/10.1016/j.enggeo.2008.06.004

ISRM 1979. Suggested methods for determining in situ deformability of rock, International Journal of Rock Mechanics and Mining Sciences \& Geomechanics Abstracts 16(3): 195-214.

ISRM 1986. Suggested method for deformability determination using a large flat jack technique, International Journal of Rock Mechanics and Mining Sciences \& Geomechanics Abstracts 23(2): 133-140. http://dx.doi.org/10.1016/0148-9062(86)90339-6

ISRM 1987. Suggested methods for deformability determination using a flexible dilatometer, International Journal of Rock Mechanics and Mining Sciences \& Geomechanics Abstracts 24(5): 123-134.

ISRM 1996. Suggested methods for deformability determination using a stiff dilatometer, International Journal of Rock Mechanics and Mining Sciences \& Geomechanics Abstracts 33(7): 733-741. http://dx.doi.org/10.1016/S0148-9062(96)93108-3

Jespersen, K.; MacLaughlin, M.; Hudyma, N. 2010. Strength, deformation modulus and failure modes of cubic analog specimens representing macroporous rock, International Journal of Rock Mechanics and Mining Sciences 47(8): 1349-1356. http://dx.doi.org/10.1016/j.ijrmms.2010.08.015

Jiang, X.-W.; Wan, L.; Wang, X.-S.; Wu, X.; Zhang, X. 2009. Estimation of rock mass deformation modulus using variations in transmissivity and RQD with depth, International Journal of Rock Mechanics and Mining Sciences 46(8): 1370-1377. http://dx.doi.org/10.1016/j.ijrmms.2009.05.004

Jurić-Kaćunić, D.; Arapov, I.; Kovačević, M. S. 2011. Novi pristup određivanju krutosti karbonatnih stijena u hrvatskom kršu [New approach to the determination 
of stiffness of carbonate rocks in Croatian karst], Građevinar 63(2): 177-185.

Kovačević, M. S.; Jurić-Kaćunić, D.; Simović, R. 2011. Određivanje modula deformacije karbonatnih stijena $\mathrm{u}$ hrvatskom kršu [Determination of strain modulus for carbonate rocks in Croatian karst], Građevinar 63(1): 35-41.

Li, J.; Wang, L.; Wang, X.; Wang, R.; Cheng, Z.; Dang, L. 2010. Research on unloading nonlinear mechanical characteristics of jointed rock masses, Journal of Rock Mechanics and Geotechnical Engineering 2(4): 357364.

Majdi, A.; Beiki, M. 2010. Evolving neural network using a genetic algorithm for predicting the deformation modulus of rock masses, International Journal of Rock Mechanics and Mining Sciences 47(2): 246-253. http://dx.doi.org/10.1016/j.ijrmms.2009.09.011

Palmstrom, A.; Singh, R. 2001. The deformation modulus of rock masses - comparisons between in situ tests and indirect estimates, Tunnelling and Underground Space Technology 16: 115-131. http://dx.doi.org/10.1016/S0886-7798(01)00038-4

Podvezko, V. 2009. Application of AHP technique, Journal of Business Economics and Management 10(2): 181-189.

http://dx.doi.org/10.3846/1611-1699.2009.10.181-189
Russo, G. 2009. A new rational method for calculating the GSI, Tunnelling and Underground Space Technology 24(1): 103-111. http://dx.doi.org/10.1016/j.tust.2008.03.002

Saaty, T. L. 1980. The analytic hierarchy process: planning, priority setting, resource allocation. New York: McGraw-Hill. 287p.

Sivilevičius, H.; Zavadskas, E. K.; Turskis, Z.; Sušinskas, S. 2012. Experimental study on technological indicators of pile-columns at a construction site, Journal of Civil Engineering and Management 18(4): 512-518. http://dx.doi.org/10.3846/13923730.2012.709958

Tutmez, B.; Tercan, A. E. 2007. Spatial estimation of some mechanical properties of rocks by fuzzy modelling, Computers and Geotechnics 34(1): 10-18. http://dx.doi.org/10.1016/j.compgeo.2006.09.005

USBR 2009. Determining in situ deformation modulus using a flexible volumetric dilatometer. Designation USBR 6575-09, Materials Engineering and Research Laboratory, code 86-68180, Technical Service Center, Denver, Colorado.

Zavadskas, E. K.; Antucheviciene, J. 2007. Multiple criteria evaluation of rural building's regeneration alternatives, Building and Environment 42(1): 436-451. http://dx.doi.org/10.1016/j.buildenv.2005.08.001

Danijela MARČIĆ. PhD Doctor in Civil Engineering, Assistant Professor in the Geotechnical Department at the Faculty of Civil Engineering University of Zagreb, Croatia. Head of Geotechnical Laboratory. Her research interests include: field and laboratory testing of soil and rock, numerical modelling, rock mechanics and geomaterials.

Anita CERIĆ. PhD Doctor in Civil Engineering, Associate Professor in the Department of Construction Management at the Faculty of Civil Engineering University of Zagreb, Croatia. Vice Dean for International Relations and Cooperation. Her research interests include: risk management, decision making, building maintenance and human resource management.

Meho Saša KOVAČEVIĆ. PhD Doctor in Civil Engineering, Full Professor in the Geotechnical Department at the Faculty of Civil Engineering University of Zagreb, Croatia. Head of Geotechnical Department. His research interests include: monitoring of geotechnical structures, tunnelling, ground improvement and numerical modelling. 